\title{
Revisiting Pre-Modern Ethnicity and Nationhood: Preface
}

\author{
Ilya Afanasyev* and Nicholas S. M. Matheou**
}

The articles published here are the first studies to emerge from a project begun a few years ago with a conference we organised around revisiting the old debate over 'ethnicity and 'nationhood before 'modernity`. Our starting point was a historiographical paradox: over the last few decades there has been a steady stream of publications on pre-modern ethnicity and national identity. Despite this fact, however, the same period saw the establishment of 'modernism< - the view that nationhood is an essentially modern phenomenon, non-existent or unimportant before 'modernity - as the dominant paradigm in ethnicity and nationalism studies (Anderson, Breuilly, Gellner, Hobsbawm). We found ourselves somewhat dissatisfied with both the hegemonic modernist paradigm and the way scholars of pre-modern history studying 'ethnicity and 'nationhood' were responding to it. We do not have space to go into a detailed critique of this vast historiographic field (or, rather, fields), but, to put it very briefly, modernism appears highly problematic because it ignores or caricatures pre-modern evidence for collective identifications and ethnonational phenomena, as well as, more dangerously, reifying the 'nation' as an objective product of 'modernity', tangible and out-there-in-the-world, in spite of the superficially constructivist language of the modernist canon's classics, not least the famous ambiguity of Anderson's simagined communities'. At the same time, the various responses to modernism seem either outright detrimental or otherwise not fully satisfactory, not least for their failure to unsettle the hegemony of modernists. Any form of primordialism only serves to compound the problem, whether by asserting the general existence of ancient or medieval 'nations', or identifying the first nation(alism) and/or 'nation-states in the shape of some particular pre-modern polity/identification. 'Third-way approaches, most commonly based on Anthony D. Smith's prolific theorising, are similarly unhelpful, accepting the 'modernist` paradigm that restricts 'real nations to the modern and contemporary worlds, while asserting ancient and medieval sethnicity` in the form of ethno-cultural groups or ethnie. Thus the primordialist teleology reappears in a different guise, as ancient and medieval ethnie are seen to develop inexorably into modern nations, while those that 'failed` are explained away by their essentially 'non-ethnic' characteristics. Finally, while scholars suggesting that we should take medieval evidence on collective identifications on its own terms have produced impressive conceptual and empirical work (to which our project is self-evidently indebted), ultimately this position leads to a theoretically untenable and historiographically self-defeating parochialism. Even if it was ever possible to discuss pre-modern evidence on its own terms, this approach restricts the relevance of researching pre-modern collective identifications to self-contained fields that cannot aspire to seriously challenge dominant paradigms in ethnicity and nationalism studies.

* Ilya Afanasyev, Birmingham Research Institute for History and Cultures, School of History and Cultures, Arts Building, University of Birmingham, Edgbaston, Birmingham, UK, B15 2TT. Email: I.Afanasyev@bham.ac.uk.

** Nicholas S.M. Matheou, Faculty of Oriental Studies, University of Oxford, 197 Goldhurst Terrace, London, UK, NW6 3ER. Email: nicholas.matheou@pmb.ox.ac.uk. 
Alongside these theoretical considerations a central problem with research on pre-modern collective identifications is the artificial chronological boundaries within the field itself. These divisions have created sometimes widely differing approaches, only loosely brought together by common reference to the few existing synoptic studies of pre-modern collective identities, such as those by Smith. These artificial chronological boundaries, and the different approaches taken by each sub-discipline, in themselves contribute to further false teleologies - whereby, in the post-Roman West for example, the image is that of early medieval 'ethnic groups', central medieval 'communities of the realm', and late medieval/early modern nationes. When our conference 'Identity, Ethnicity and Nationhood before Modernity: Old Debates and New Perspectives` took place in April 2015, we hoped that by bringing together specialists of varying periods, we would problematise these artificial distinctions, deconstruct such false teleologies, and create a real basis for cross-comparison. Out of the conference we developed an international research network based at The Oxford Centre for the Humanities (TORCH) that includes established, leading figures in the field, as well as young scholars engaged with the theme (torch.ox.ac.uk/identity). All members subscribe to common notion that there is much more to be done with integrating pre-modern examples into the broader field, as well as in developing further cooperation between scholars working on different regions, periods and materials relevant to the debate over modern and pre-modern ethnic phenomena.

The articles brought together here - four of which originate in papers presented at the conference - reflect this intention, ranging the full span of the middle ages from Late Antiquity to the fifteenth century. James M. Harland's contribution starts us in the fourth to sixth centuries, with the much disputed reconfiguration of self-identifications in the period between the end of Roman imperial rule and the emergence of 'Anglo-Saxon England. The author masterfully deconstructs both literary and archaeological approaches that seek to construct and reify the image of a fixed 'postcolonial British identification, one which explicitly Others both the Roman imperial order and incoming 'Germanic' Anglo-Saxons. But rather than stop at a simple deconstruction, Harland goes on to demonstrate that there are salient identifications and semiotic systems present in both literary and material evidence, not in terms of fixed ethnicities, but of new military ideologies grounded in particular iterations of Romanness and respondent to specific conjunctural conditions.

Patrick Wadden's article takes us across the sea to early medieval Ireland, addressing the undeniable fact that from the earliest seventh-century Irish texts onwards there are consistent discursive explorations of Irish historic unity as an 'imagined community - so much so that it appears that learned elites 'were preoccupied with this very notion'. Traversing the various instantiations, the author shows how, despite differences in specifics, each variation attempts to deal with perceived ethno-cultural unity among the scholars writing early Irish texts and their patrons in the political elite, despite the social reality of political and ecclesiastical fragmentation. Yet Wadden shows how this perceived 'national unity< is likely to have been novel (and not without opponents drawing on older traditions that ethnicised different social-legal classes), having been 'forged by seventh-century churchmen` in specific times and places for specific purposes. Claire Weeda's contribution moves us into the central middle ages, examining both synchronically and diachronically how monks in continental Europe from the tenth century on constructed discourses of ethnic stereotypes - the characteristics, virtues and vices of various peoples. In the new context of the 'Twelfth Century Renaissancer, however, and under the influence of Galen's views on the body and its humours, writers began to tie these stereotypes to bodily characteristics and bodies' climactic conditioning. 
As such, they developed a discourse in which the body's materiality - and its concomitant ability to act as a stand-in rethnotype - was instrumentalised as part of a conjunctural redefinition of ethnic phenomena, a moment in the 'constant process that engages with social reality and at the same time shapes it‘.

Ioannis Stouraitis' article brings much needed perspectives from the eastern medieval world, in the shape of the Eastern Roman Empire or 'Byzantium‘. The author explicitly situates his material in the context of the broader debate over ethnicity and nationhood before modernity, as well as the emerging debate within Byzantine studies over the nature of 'Byzantine Romanness', forcefully argued in recent scholarship to be an example of medieval nationhood. Ranging from the seventh to fifteenth centuries, and across various times, places and sources, Stouraitis argues instead that despite the undisputed continuity of Roman self-identification in the eastern empire, this is a remarkable case of radical transformation in a pre-modern social order's collective identity discourse, with shifting social conditions in each conjuncture producing very different content and associations for the Roman category. Finally, Andrea Ruddick's contribution turns to late medieval England, and the phenomenon of actors 'becoming English by changing in political allegiance, despite dominant contemporary discourses' construction of 'racial understandings of ethnic phenomena and nationhood, grounded in birth, blood, and heredity. The author demonstrates how these apparently anomalous formulations are intended to highlight the antithetical quality of actors changing allegiances to those other than their 'naturak national identification. Indeed, the fixed and essentialised understandings of ethnicity were such that, Ruddick argues, even denization - a kind of 'civic naturalisation` granting the rights of native-born English - did not change how such actors were perceived, but merely permitted them to be treated in certain circumstances as if they were English, leaving them vulnerable to persecution in moments of 'national< wars and revolts.

These articles then provide a more than fitting start to the project of revisiting both modern and pre-modern ethnicity and nationhood. We are currently in the process of editing a volume specially dedicated to this topic. There we will provide an in-depth theoretical critique of previous approaches and set out a new direction able to both recognise the socially-constructed nature of ethnic phenomena across time and place, as well as their potentiality to be turned into a material force under specific political-economic, social, cultural and ideological conditions. 